\title{
ANTICUERPOS CONTRA EL VIRUS DE LA ANEMIA INFECCIOSA AVIAR EN REPRODUCTORAS Y NIVELES DE TRANSFERENCIA PASIVA A LA PROGENIE
}

\author{
Chicken Infectious Anemia Virus Antibodies in B Reeder B roilers ANd \\ Levels of Passive Transference to the Progeny
}

\author{
Benjamín Quezada A. ${ }^{1}$, Eliana Icochea D. ${ }^{1,2}$, Mónica Alba Ch. ${ }^{1}$ y Rosa Gonzáles V. ${ }^{1}$
}

\section{Resumen}

El presente estudio se llevó a cabo en tres granjas de reproductoras de carne de la línea Cobb para determinar el nivel y persistencia de anticuerpos al virus de la Anemia Infecciosa Aviar (CIAV) en aves que fueron fueron vacunadas en la etapa de levante. Las aves de una granja (G1) se vacunaron vía oral y las aves de otra granja (G2), por vía intramuscular. Las aves de la tercera granja (G3) no fueron vacunadas pero estuvieron expuestas al virus de campo como todas. Las aves se muestrearon a los 30, 45 y 60 semanas de edad. Además, se evaluó el nivel y porcentaje de transferencia de anticuerpos a la progenie de estos lotes de reproductoras al día de edad. Las muestras fueron procesadas en forma conjunta con la prueba de ELISA para CIAV de los Laboratorios IDEXX. Se detectó una seroconversión total en las granjas vacunadas A y B a las 30 semanas, mientras la granja no vacunada tuvo el $10.5 \%$ de aves negativas, en tanto que todas las aves seroconvirtieron a las 45 y 60 semanas de edad; sin embargo, se observó que los títulos de anticuerpos en las reproductoras descendieron a las 60 semanas en las tres granjas. La transferencia pasiva de anticuerpos a la progenie fue inferior en la granja G1 que en las otras dos granjas.

Palabras clave: anemia, CIAV, ELISA, anticuerpo

\section{Abstract}

Three poultry farms (A, B and C) of Cobb breeder broilers were blood monitored at 30,45 , and 60 weeks of age to assess the level and persistence of sera antibodies against chicken infectious anemia virus (CIAV) under two vaccination strategies. Hens in farm A were vaccinated via drinking water and hens in farm B via intramuscular (IM) during the rearing period, whereas farm $\mathrm{C}$ was only exposed to a field virus. Progeny's sera was evaluated at one day old to determine antibodies level and percent of transference. Serum samples were analyzed by a commercial ELISA test. A total seroconversion was detected in farms $\mathrm{A}$ and $\mathrm{B}$ at the age of 30 weeks while $10.5 \%$ of layers in farm $\mathrm{C}$ were

\footnotetext{
${ }^{1}$ Laboratorio de Patologia Aviar, Facultad de Medicina Veterinaria, Universidad Nacional Mayor de San Marcos, Lima

${ }^{2}$ E-mail: eliana.icochea@gmail.com
} 
negative. All hens in the three farms seroconverterd at 45 and 60 weeks old, but antibody titers decreased at the age of 60 weeks. The passive transference of antibodies to the progeny was much lower in farm A as compared to the other two farms.

Key words: anemia, CIAV, ELISA, antibody

\section{INTRODUCCIÓN}

El virus de la Anemia Infecciosa Aviar, conocido también como CIAV (Chicken Infectious Anemia Virus), es considerado como el tercer virus responsable de inmunosupresión en pollos (Dávila, 2001). Este virus es único dentro del género Gyrovirus, incluido dentro de la familia Circoviridae (Pringle, 1999), y está presente en todos los países donde existen explotaciones avícolas comerciales (McNulty, 1991). El virus tiene una remarcada estabilidad química y térmica, por lo que se dificulta su control (Coombes y Crawford, 1996).

El CIAV puede transmitirse en forma vertical y horizontal, siendo la primera la más importante, ya que a través de ella se presentan los cuadros clínicos y mortalidad en la progenie (Bülow y Schat, 1997). Para verificar el nivel de anticuerpos protectivos y su persistencia se recomienda el monitoreo serológico a través de la prueba de ELISA, ya que es una de las pruebas más sencillas y económicas.

Bajo este contexto, el presente trabajo tuvo por finalidad el monitoreo serológico de anticuerpos contra CIAV en gallinas reproductoras vacunadas y no vacunadas en tres puntos críticos de la producción para determinar el nivel de protección de los anticuerpos presentes, evaluar el nivel de transferencia pasiva al día de edad, y establecer si existen diferencias significativas entre los programas de vacunación y el programa de exposición natural.

\section{Materiales y Métodos}

Se trabajó con madres reproductoras de la línea Cobb Vantress de tres granjas comerciales correspondientes a los departamentos de Lima (vacunadas) y Arequipa (no vacunadas). Una granja utilizaba la vacuna contra el CIAV, vía agua de bebida a las 13 semanas de edad con la cepa CUX-1 (G1); otra granja usaba la vía intramuscular a las 10 semanas de edad con la cepa 26P4 (G2); en tanto que en la tercera no se vacunó contra el CIAV (G3).

Se colectó sangre a 171 gallinas a las 30,45 y 60 semanas de edad y a 147 pollitos de un día de edad derivados de los lotes de las gallinas bajo estudio. Las muestras de sangre fueron recolectadas por punción de la vena alar y mantenidas a temperatura ambiente por 2-3 horas para la obtención del suero, siendo estos almacenados a $4{ }^{\circ} \mathrm{C}$ hasta el momento de su lectura. La detección de anticuerpos contra CIAV se realizó mediante una prueba de ELISA competitivo usando un kit comercial (Laboratorios IDEXX).

Se utilizó un análisis de varianza factorial para la comparación de títulos de anticuerpos entre granjas, además de la prueba de comparaciones múltiples de Tukey. Para la evaluación de la transferencia de anticuerpos a la progenie en las diferentes etapas productivas se utilizó un diseño en bloques completamente randomizados y la prueba de Duncan para determinar las diferencias entre grupos. 
Cuadro 1. Niveles de anticuerpos contra el virus de la Anemia Infecciosa Aviar (promedio geométrico -PG-, coeficiente de variación-CV- y el porcentaje de transferencia a la progenie -PT\%-) de gallinas reproductoras de carne de la línea Cobb Vantress que fueron sometidas a dos esquemas de vacunación

\begin{tabular}{lccccccccc}
\hline \multirow{2}{*}{$\begin{array}{l}\text { Tipo de } \\
\text { vacunación }\end{array}$} & \multicolumn{3}{c}{30 sem } & \multicolumn{3}{c}{45 sem } & \multicolumn{3}{c}{60 sem } \\
\cline { 2 - 10 } & PG & CV & PT & PG & CV & PT & PG & CV & PT \\
\hline Oral (G1) & 6893 & 28.1 & 29.32 & 6929 & 28.6 & 34.68 & 6359 & 32.6 & 40.82 \\
IM (G2) & 7769 & 20.3 & 80.15 & 5946 & 36.8 & 64.50 & 4874 & 44.8 & 85.20 \\
Control (G3) & 5131 & 46.2 & 73.22 & 7046 & 28.2 & 81.31 & 6631 & 32.4 & 95.52 \\
\hline
\end{tabular}

Cuadro 2. Niveles de anticuerpos contra el virus de la Anemia Infecciosa Aviar (promedio geométrico -PG-, y coeficiente de variación -CV-) en pollitos de carne de la línea Cobb Vantress de un día de edad, cuyas madres fueron sometidas a dos esquemas de vacunación

\begin{tabular}{|c|c|c|c|c|c|c|}
\hline & \multicolumn{2}{|c|}{ BBs rep 30 sem } & \multicolumn{2}{|c|}{ BBs rep 45 sem } & \multicolumn{2}{|c|}{ BBs rep 60 sem } \\
\hline & PG & $\mathrm{CV}$ & PG & $\mathrm{CV}$ & PG & $\mathrm{CV}$ \\
\hline \multicolumn{7}{|l|}{ Oral (G1) } \\
\hline Macho & 1828 & 109.3 & 2567 & 77.2 & 2107 & 90.4 \\
\hline Hembra & 2268 & 77.4 & 2241 & 62.8 & 3085 & 65.5 \\
\hline \multicolumn{7}{|l|}{$\mathrm{IM}(\mathrm{G} 2)$} \\
\hline Macho & 6425 & 30.6 & 3461 & 63.6 & 5567 & 42.1 \\
\hline Hembra & 6029 & 38.5 & 4804 & 48.1 & 2739 & 82.1 \\
\hline \multicolumn{7}{|l|}{ Control (G3) } \\
\hline Macho & 3946 & 60.8 & 6491 & 31.4 & 6630 & 65.7 \\
\hline Hembra & 3568 & 65.7 & 4983 & 49.0 & 6038 & 33.3 \\
\hline
\end{tabular}

\section{Resultados}

Los niveles de anticuerpos desarrollados por las reproductoras contra el virus de la Anemia Infecciosa Aviar y el porcentaje de transferencia a la progenie se muestran en el Cuadro 1, en tanto que los títulos de anticuerpos en los sueros de los pollitos de un día de edad se muestran en el Cuadro 2.
Las aves de las granjas vacunadas contra CIAV mostraron niveles de anticuerpos protectivos durante todas las tres etapas de producción, aunque con tendencia a disminuir hacia la semana 60, especialmente en las aves vacunadas por vía IM, donde se observó una disminución del 37\%. El 10.5\% de las aves no vacunadas resultaron negativas al CIAV a las 30 semanas de edad. 
Los títulos de anticuerpos fueron más elevados a las 30 semanas de edad en las aves vacunadas con relación al grupo control. Sin embargo, no hubo diferencias significativas a las 45 y 60 semanas de edad.

La transferencia de anticuerpos a los pollitos fue más efectiva en las aves vacunadas por vía IM y en aquellas no vacunadas con relación al grupo vacunado por vía oral. Por otro lado, no hubo diferencia significativa en la transferencia de anticuerpos con relación al sexo de los pollitos, aunque se pudo observar una tendencia a obtenerse una mayor transferencia en los machos. Así mismo, se observó una mejor transferencia a las 60 semanas de edad.

El 90\% (45/50) de los pollitos de un día de edad fueron positivos al CIAV.

\section{Discusión}

Los resultados obtenidos mostraron diferencias estadísticas significativas $(\mathrm{p}<0.05)$ favorables en los títulos de anticuerpos de las reproductoras provenientes de granjas vacunadas con relación a las no vacunadas cuando las aves tenían 30 semanas de edad; ya que a edades mayores, los niveles de anticuerpos de las reproductoras de las granjas no vacunadas se elevaron hasta obtener títulos similares a las vacunadas.

La caída de anticuerpos en las aves vacunadas por vía IM pudo haberse debido a que la vacuna contiene una cepa muy atenuada que no llega a invadir los tejidos de los órganos reproductivos y mantener latente al virus, aún después de la seroconversión en las gallinas reproductoras, como al parecer sucede con la cepa utilizada en la vacuna administrada vía agua de bebida (Cardona et al., 2000).

El incremento del nivel de anticuerpos en las reproductoras no vacunadas a las 45 semanas de edad hace suponer que las aves que resultaron negativas podrían haber estado en vías de infección a las 30 semanas de edad. Estos resultados no coinciden con estudios europeos donde encontraron que las reproductoras eran positivas al CIAV durante toda la etapa productiva (De Herdt et al., 2001). Por otro lado, se encontró un patrón de persistencia de los niveles de anticuerpos diferente a otros estudios (Imai et al., 1993), posiblemente debido a las condiciones ambientales, principalmente al grado de desafío del CIAV en campo.

Los resultados obtenidos en la progenie de las reproductoras mostraron una alta variabilidad. Estudios realizados por Cardona et al. (2000) demostraron que algunas cepas del CIAV, incluyendo una similar a la que se utilizó en el agua de bebida (CUX-1) permanecen en los tejidos reproductivos de las reproductoras durante largo tiempo luego de la seroconversión. En ese estudio se concluyó, además, que la presencia de anticuerpos en la circulación no elimina los virus presentes en los tejidos reproductivos y que es probable que no prevenga la transmisión vertical del virus; situación distinta es la que se presenta en las reproductoras vacunadas vía intramuscular, ya que al utilizar una cepa muy atenuada y adaptada al embrión de pollo, es posible que no llegue a invadir los tejidos reproductivos y, por lo tanto, los anticuerpos séricos son transferidos en gran porcentaje a su progenie, tal y como sucedió en el presente estudio.

\section{Conclusiones}

? Las reproductoras vacunadas contra el virus de la Anemia Infecciosa Aviar desarrollaron títulos protectivos durante toda la campaña, aunque los títulos de las reproductoras vacunadas por vía oral mostraron una mejor persistencia.

? Las reproductoras vacunadas por vía intramuscular y las no vacunadas tuvieron un mayor porcentaje de transferen- 
cia de anticuerpos a su progenie en todas las etapas de producción.

? No todas las aves expuestas al virus de campo seroconvirtieron en la etapa inicial de producción, por lo que dejar de vacunar es una política que implicaría mucho riesgo y no sería recomendable.

\section{Literatura Citada}

1. Bülow VV, Schat KA. 1997. Chicken infectious anemia. In: Calnek BW (ed). Diseases of poultry. $10^{\text {th }} \mathrm{ed}$. Iowa, USA: Iowa State University Press. p 739-756.

2. Cardona CJ, Oswald WB, Schat KA. 2000. Distribution of chicken anaemia virus in the reproductive tissues of specific-pathogen-free chickens. J Gen Virol 81: 2067-2075.

3. Coombes AL, Crawford GR. 1996. Chicken anemia virus: a short review. World Poultry Sci J 52: 267-277.
4. Dávila E. 2001. Protección integral del sistema inmune de los pollos con el uso adecuado de vacunas y programas de vacunación. Mundo Avícola y Porcino 37: 15-16.

5. De Herdt P, Van de Bosh G, Ducatelle R, Uyttebroek E, Schrier C. 2001. Epidemiology and significance of chicken infectious anemia virus infections in broilers and broiler parents under nonvaccinated European circumstances. Avian Dis 45: 706-708.

6. Imai K, Mase S, Tsukamoto K, Hierra H, Matsumura T, Yuasa N. 1993. A long term observation of antibody status to chicken anaemia virus in individual chickens of breeder flocks. Res Vet Sci 54: 392-396.

7. McNulty MS. 1991. Chicken anemia agent: a review. Avian Pathol 20: 187203.

8. Pringle CR. 1999. Virus taxonomy. Arch Virol 144: 2065-2070. 